\title{
3 Research Square

\section{Assessment of health hazards and risk perceptions of market garden producers towards the effects of pesticides in Western Region Cameroon}

Bernard christian Kaldjob Mbeh ( $\square$ Christianbernard.kaldjob@yahoo.fr )

Institut de recherche agricole pour le developpement https://orcid.org/0000-0003-2461-2135

Precillia Tata Ngome

Institut de recherche agricole pour le developpement

Emmanuel Douya

Université de Yaoundé II: Universite de Yaounde II

Andre Nso Ngang

Institut de recherche agricole pour le developpement

Bamou Tankoua Lydie

Universite de Yaounde II

Brice Hermann Simo

Institut de recherche agricole pour le developpement

\section{Research Article}

Keywords: Cameroon, vegetables producers, symptoms of poisoning, Ordered Logit model, Agrochemical pesticides, and risk awareness

Posted Date: February 1st, 2022

DOI: https://doi.org/10.21203/rs.3.rs-1272132/v1

License: (9) This work is licensed under a Creative Commons Attribution 4.0 International License.

Read Full License 


\section{Abstract}

Objective and Methods

The spraying of chemicals pesticides is a key factor for the improved quality and productivity of agricultural products. Nevertheless, the increased health issues among the agrarian population in Africa, and particularly in Cameroon, involves to lay an emphasis on how producers' risk perception toward pesticides can contribute to mitigate their effects. The risk assessment of pesticides on the literature focuses mainly on the pesticide itself, but the studies on producers' risk perception and the drivers of this perception on their behavior are insufficiently known. Therefore, this article assess the health risks and risk perceptions of 560 producers towards the effects of pesticides in 7 subdivisions of Western region Cameroon. A cross-sectional dataset was use during the period of July 2020 to May 2021 for our interviews and an ordered Logit model was use to perform our analyses.

Results

The results showed $74.62 \%$ and $63.93 \%$ of producers attested that herbicides and insecticides are among the extremely hazardous products. Otherwise, excessive sweating (61.07\%), general tiredness (61.96\%), nausea and vomiting $(54.46 \%)$ and headaches $(53.04 \%)$, were among the main symptoms of health issues reported. In addition, some socioeconomic characteristics including health, age, education, training and awareness of producer were the main significant drivers of risk perception.

Conclusion and recommendations

Our observations led to fundamental implications for policymakers, as the overuse of pesticides and their negative effects on the health of Farmers may be aggravated, if there is no support by the integration of social norms. Furthermore, more training program from agricultural extension services should place emphasis on imparting basic precautionary knowledge for limited producers.

\section{Introduction}

The spraying of chemicals pesticides in modern agriculture is a major component with evidence benefits on yields and product quality. ${ }^{[1]}$ Indeed, according to ${ }^{[2,3]}$, it is more than 3 billion tons of hazardous chemicals pesticides that are used each year to control weeds, pests and plants diseases by at least 1.5 billion people worldwide who are involved in agriculture-related activities. And as in other developing countries of sub-Saharan Africa, Cameroon's agricultural sector also consume massively agrochemicals pesticides with more than 1.373 tons of pesticides sprayed only in $2018 .{ }^{[4,5]}$

Over the past 10 years, with the growing population, the demand for market garden products and other food crops has increased in the country. ${ }^{[6]}$ Thus, to guarantee the crop protection and then reduce the supply and demand gap, heavy amounts of pesticides have been used across the country. ${ }^{[7,8]}$ Indeed ${ }^{[9]}$ 
attested that since 2015, it has been recorded more than 600 pesticides products in Cameroon, with dominant products being insecticides (33.93\%); herbicides (26.55\%) and fungicides $(24.26 \%)$.

Although very clear instructions about the judicious use of chemicals pesticides are available in Cameroon's pesticide management legislation, and specifically on the labels of the recommended products, the regulation of their residues on food and nonfood crops has not been meticulous at all ${ }^{[6]}$. Usually, Cameroonian producers do not fully conform to the standard pesticides practices in monitoring harmful pests and diseases. ${ }^{[9]}$ As consequences, the overuse of chemicals pesticides have been highly associated with the health hazards and acute pesticide poisonings who tragically claim many lives worldwide each year. Indeed, ${ }^{[10,11]}$ estimate that acute pesticide poisonings affect nearly 3 million people and they are responsible for more than 20.000 accidental deaths each year, which generates some high economic costs in developing countries such as Cameroon. ${ }^{[12,13-14]}$

Considering the above stylized facts, the producer's perception towards overuse of pesticides and their effects is very important and should be considered as an important issue for the harmful effects on health and their closer environment. In the literature, the risk assessment of pesticides uses focuses mainly on the pesticide itself, through studies like ${ }^{[15,16]}$, on the toxicological effects of pesticides, or the one from ${ }^{[15]}$ on the development of formulations to reduce pesticides doses and exposure, or finally on contamination routes for the producer like the study of. ${ }^{[18]}$ But the studies on producers' risk perception of pesticides and the influence of this perception on their behavior are insufficiently known. Nevertheless, some studies indicate that the use of pesticides by producers and their perception are sometimes related to one another. Indeed, ${ }^{[19]}$ observe early that perception affects peoples' behavior and their careful management of a risk. So as an example, ${ }^{[20,21]}$ have examined the relationship between risk perception and household's knowledge regarding water pollution and its potential effect on human health. Also, ${ }^{[22,}$ ${ }^{16-26]}$ concluded that perception is fundamentally influenced by a producer's education.

Other authors such as ${ }^{[24,25-26]}$ defined the risk perception as a subjective assessment of the probability of a specific type of accident occurring and the extent to which the individual concerned values the consequences. According to ${ }^{[2]}$, people receive signals and stimuli from their surroundings and use these to develop their perceptions. Hence, when producers observe adverse pesticide effects, they may be aware of these effects because of possible health issues. Even if the perception of risk goes beyond the individual, as it is a social and cultural construct that reflects the symbols, values, history and ideology of a society.

In the line with this, we therefore postulate in this paper that the more producers perceive the effects of pesticides as risks to their health, the more vigilant they will be with their handling. Our main objective is thus to quantify risk perceptions of pesticides and adverse health effects of exposure to pesticides among the market garden producers of western region in Cameroon. The purpose of the results of this research is to serve as a decision-making tool for agricultural and health policy makers to design more effective policies for sustainable agriculture. 


\section{Analysis of socioeconomic factors underlying producers' perception: A Ajzen's Theory of Planned Behavior (TPB)}

As previously stated, most Camerounian market garden producers are not informed and trained enough on the recommended measures against the effects of pesticides and their toxicity. This problem has thus become an important question that has driven researchers to develop theoretical model on the basis of existing studies in the literature. Based on ${ }^{[2]}$ observations, this model is especially supported by the Theory of Planned Behavior (TPB), an improvement of the early theory of reasoned action which has its foundation in psychology. A pioneer of this theory is the American psychologist Ajzen, who in the early 1990s established a link between some convictions and the individual's behaviors. ${ }^{28]}$

Over the past decade Ajzen's theory has then been recognized in various fields of research and implemented to understand a wide diversity of human behavior. ${ }^{[29,30-31]}$ As an example, the earlier study of ${ }^{[26]}$ on producers' perception of pesticides, the recent one of ${ }^{[32,33]}$ on producers' perception over pesticides effects, or the research of ${ }^{[34]}$ are among the recent studies who have applied this theory. Indeed, the relevance of this theory's approach to studies of producers' perceptions of pesticides stems from the fact that producers' pesticide use behavior is not only influenced by institutional factors like pesticide prices, distribution chains, access to market information, but also unobservable emotional factors such as motivating forces on a single decision maker. ${ }^{[2]}$

Technically, Ajzen's theory describes how an individual shapes his perception by taking into account attitude, subjective norms and perceived behavioral control. In our study, producers' perceptions toward pesticides are influenced by sociodemographic characteristics like (Age, educational level, farm income, rural cooperative membership, land ownership, agricultural knowledge and experience ...), and by family members characteristics (family size and family labor, marital Statut, health diseases effects...) (Fig. 1). Regarding ${ }^{[2]}$, our subjective criteria influencing producers to adopt a particular behavior can be associated with the level of consumption of agricultural products.

From an empirical point of view, ${ }^{[31]}$ concluded that the significant influence of a related subjective norm can improve the perception and probability of executing a particular behavior. Also, ${ }^{[33,35]}$ discussed about the individual's practice and obstacles that may inhibit the perceived behavioral control and then influence farmers' perception of pesticide. The authors identified seven main determinants treated as antecedents to producers' risk perception. Since the complexity of the health diseases occurrence, our understanding of the relationship between individual's factors such as producer's age, level of education, agricultural income and producers' perceptions could thus be improved by analyzing these characteristics.

The empirical evidence of ${ }^{[36]}$ considered producers' age as an important factor in differentiating exposure to pesticide toxicity. Similarly, some studies of ${ }^{[37,29]}$ indicated that there is a significant and positive correlation between level of education, knowledge and producers' perception of quantity of pesticides to be sprayed. Fundamentally, knowledge refers to a set of information acquired through 
education. In fact, knowledge of pesticide effects can familiarize patients with health issues and help them take preventive measures in a timely method. Therefore, awareness of pesticides effects is considered as the attention and sensitivity of an individual to health issues. In the rural setting of Cameroon, market garden producers achieve awareness through the rural community, agricultural field officers, health agents, and some suppliers in the rural markets.

\section{Materials And Methods}

\section{Study area}

This study was precisely carried out in the Noun Division, West region of Cameroon (Fig. 2). It is located roughly $5^{\circ} \mathrm{N}$ by $10^{\circ} 30 \mathrm{E}$. The river Noun separates two main plateaus, one of which is $1,200 \mathrm{~m}$ high, the other 1,500m high. These two plateaus have been beveled during the past geological times and covered by volcanic materials which have altered relief and disturbed the hydrography pattern. The local population cultivates their land with great care in the sprawling part of the plateaus but without any care on the escarpments. They are grouped around the seven main localities (Magba, Djinoun, Koutaba, Foumban, Kouoptamo, Foumbot, and Massagam), which made up our survey area.

The primary data used for our empirical analysis were obtained from a survey conducted within the period from July 2020 to May 2021 in 7 subdivisions which form one of the important agricultural production pool of the country, due to their fertile land. (Tab. 1) below presents the distribution of subsamples by subdivisions. The Noun Division was selected for two reasons: firstly, because of the high production of market garden products which is approximately $30-40 \%$ of the whole vegetable production

of the country. ${ }^{[38]}$ Secondly, because of the significant consumption of chemical pesticides in this Division. ${ }^{[8]}$ But also, as a result of the presence and organization of rural cooperatives, the Socioeconomic importance of agriculture for rural households, the intensity of agricultural activities, and finally the soil and climate characteristics favourable to agricultural production.

\section{Survey design and data collection}

The multistage sampling technique was applied for the present study. In the first step, the stratified random sampling technique was used, and Noun division was geographically divided into three main zones the North, the West and the Centre (Fig. 2). In the second step, one district was selected from each geographical stratum, followed by the selection of villages per district and finally market garden producers per village (Tab. 1). In the third stage, a random sample technique was used, and a sample of 560 market garden producers was obtained. 
Table 1

Distribution of market garden producers by survey location

\begin{tabular}{|llll|}
\hline Localities & $\begin{array}{l}\text { Number of producers } \\
(\mathbf{N})\end{array}$ & $\begin{array}{l}\text { Percentages } \\
(\%)\end{array}$ & Total \\
\hline Foumbot & 130 & 23,21 & 130 \\
\hline Koutaba & 80 & 14,28 & 80 \\
\hline Djinoun & 80 & 14,28 & 80 \\
\hline Kouoptamo & 70 & 12,5 & 70 \\
\hline Massagam & 100 & 17,85 & 100 \\
\hline Magba & 50 & 8,92 & 50 \\
\hline Foumban & 50 & 8,92 & 50 \\
\hline Total & $\mathbf{5 6 0}$ & $\mathbf{1 0 0}$ & $\mathbf{5 6 0}$ \\
\hline
\end{tabular}

Source: Authors' construction 2021

Prior to the field survey, verbal approval was obtained from the traditional chief and his senior advisors in the respective villages to conduct face-to-face interviews with the producers. Face-to-face interviews are a more sophisticated way of collecting adequate information, although they are expensive. Finally, out of 560 interviewed producers, 130 were from the Foumbot village, 100 were from the village of Massagam, and 80 were from the Koutaba and Djinoun respectively. All farmers included in the sample list were obtained from 7 villages. The interview process was conducted from July 2020 to May 2021

The main informations collected on the surveys were on household socio-demographic characteristics, symptoms of poisoning, and risk perceptions of agrochemicals pesticides effects. After data springcleaning, 560 valid observations were finally used for the study. (Tab. 2) presents a descriptive statistics of the selected variables. 
Table 2

Distribution of descriptive statistic of socioeconomic variables

\begin{tabular}{|c|c|c|c|c|}
\hline Variables & Description & Code & Value & S.D \\
\hline Age & Age of producer (head of farm) & Year & 42.587 & 12.009 \\
\hline \multirow[t]{2}{*}{ Education } & \multirow{2}{*}{$\begin{array}{l}\text { Level of education of the producer (head } \\
\text { of farm) }\end{array}$} & \multicolumn{3}{|l|}{$0=$ illiterate } \\
\hline & & $\begin{array}{l}1=\text { Primary } \\
2=\text { Secondary } \\
3=\text { Tertiary }\end{array}$ & 1.442 & 0.800 \\
\hline Exp & $\begin{array}{l}\text { Producer experience in years of large- } \\
\text { scale farm management }\end{array}$ & Number of Year & 15.180 & 9.877 \\
\hline Membership & $\begin{array}{l}\text { Whether the producer is an Agricultural } \\
\text { Cooperative member }\end{array}$ & $1=$ Yes $0=$ No & 0.617 & 0.486 \\
\hline Area & Size of land operated by farms & hectare & 2.683 & 1.877 \\
\hline Ownership & Land ownership by the producer & $1=$ Yes $0=$ No & 0.941 & 0.235 \\
\hline Pesti_training & $\begin{array}{l}\text { Whether the producer have received a } \\
\text { training on pesticides management }\end{array}$ & $1=$ Yes $0=$ No & 0.216 & 0.41 \\
\hline Size & $\begin{array}{l}\text { The proportion of family labors in the } \\
\text { total farm labor force }\end{array}$ & $\begin{array}{l}\text { Number of people } \\
\text { in the house }\end{array}$ & 7.235 & 3.626 \\
\hline Health & $\begin{array}{l}\text { Whether the producer has had health } \\
\text { problems }\end{array}$ & $1=$ Yes $0=$ No & 0.748 & 0.434 \\
\hline Knowledge & $\begin{array}{l}\text { Producer has a good knowledge on } \\
\text { pesticides effects }\end{array}$ & $1=$ Yes $0=$ No & 0.423 & 0.465 \\
\hline Awareness & $\begin{array}{l}\text { Whether the producer is aware of the } \\
\text { dangers of pesticides }\end{array}$ & $1=$ Yes $0=$ No & 0.412 & 0.457 \\
\hline Source: Auth & construction 2021 & & & \\
\hline
\end{tabular}

\section{Estimation Technique and data analysis}

In order to determine the degree of correlation and the significance of the link between the perception of market gardeners and socioeconomic characteristics, Pearson's point biserial correlation tests and Spearman's correlation tests were used. Factors which influence producers' perception of the effects of pesticides are estimated by regressing one dependent variable with eleven independent variables.

This model is a continuation of the binary ordered Logit regression which is used when the dependent variable is in binary or rank form. Based on the approach of ${ }^{[39]}$, who estimate risk perception, we also adopt the ordered Logit as an estimation technique. Indeed, this model can be specified to identify producer responses that influence the perceived health risks of pesticide use in market garden production such as: 
$P_{i}^{*}=\beta^{\prime} Y_{i}+\delta_{i}$

With $P_{i}^{*}$ the unobserved and continuous measure of health-related risk perception of using pesticides for market garden production, $Y_{i}$ is a vector of sociodemographic variables, $\beta$ a vector of parameters to be estimated and $\delta_{i}$ is a disturbance term supposed to be normally distributed. And since $P_{i}^{*}$ is unobserved, we evaluate the coded discrete responses of the variable $P_{i}$ as follows:

$$
P_{i}^{*}=\left\{\begin{array}{ccc}
1 & \text { if } & -\infty \leq P_{i}^{*} \leq \lambda_{1} \text { (not hazardous) } \\
2 & \text { if } & \lambda_{1} \leq P_{i}^{*} \leq \lambda_{2} \text { (very hazardous) } \\
3 & \text { if } & \lambda_{2} \leq P_{i}^{*} \leq \lambda_{3} \text { (fairly hazardous) } \\
4 & \text { if } & \lambda_{3} \leq P_{i}^{*} \leq \lambda_{4} \text { (strongly hazardous) } \\
5 & \text { if } & \lambda_{4} \leq P_{i}^{*} \leq \lambda_{+\infty} \text { (extremely hazardous) }
\end{array}\right.
$$

While considering the maximum likelihood method which provides consistent and asymptotic estimators we can alternatively estimate the vectors of $\beta^{\prime}$ parameters and $\lambda^{\prime}$ thresholds according to. ${ }^{[2]}$ The marginal effects of the dependent variables were estimated using the coefficients of the ordered Logit model. The probabilities associated with the coded risk perception responses of the farmers in the ordered Logit model are given as follows:

$$
\begin{aligned}
& T_{1}(0)=T_{r}\left(P_{i}=0\right)=T_{r}\left(P_{i}^{*} \leq \lambda_{1}\right)=T_{r}\left(\beta Y_{i}+\delta_{i} \leq \lambda_{1}\right) \\
& =T_{r}\left(\delta_{i} \leq \lambda_{1}-\beta Y_{i}\right)=\varphi\left(\lambda_{1}-\beta Y_{i}\right) \\
& T_{i}(1)=T_{r}\left(P_{i}=1\right)=T_{r}\left(\lambda_{1} \leq P_{i}^{*} \leq \lambda_{2}\right)=T_{r}\left(\delta_{i} \leq \lambda_{2}-\beta^{\prime} Y_{i}\right)-T_{r}\left(\delta_{i} \leq \lambda_{1}-\beta Y_{i}\right)=\varphi\left(\lambda_{2}-\beta Y_{i}\right)-\varphi\left(\lambda_{1}-\beta^{\prime} Y_{i}\right) \\
& T_{i}(k)=T_{r}\left(P_{i}=k\right)=T_{r}\left(\lambda_{k} \leq P_{i}^{*} \leq \lambda_{\hat{k}+1}\right)=T_{r}\left(\delta_{i} \leq \lambda_{k+1}-\beta Y_{i}\right)-T_{r}\left(\delta_{i} \leq \lambda_{i}-\beta Y_{n}\right) \\
& =\varphi\left(\lambda_{k^{+}+1}-\beta Y_{i}\right)-\varphi\left(\lambda_{k}-\beta Y_{i}\right) \\
& T_{i}(K)=T_{r}\left(P_{i}=K\right)=T_{r}\left(\lambda_{k} \leq P_{i}^{*}\right)=1-\varphi\left(\lambda_{k}-\beta Y_{i}\right)
\end{aligned}
$$

With $k$ symbolizing a marginal response of the producer; $T_{r}\left(P_{i}=K\right)$ representing the probability that a market garden producer $i$ give a responds $k, \varphi($.$) is the cumulative Logit distribution function. Appreciated$ health hazards is theoretical depend on the quantity and quality of pesticides sprayed by the market garden producers of the sample. Risk perception is a latent variable as producers had to choose one answer among a set of five possible options. The positive signs of the parameters $\beta$ show higher healthrelated risk towards the use of pesticides, while negative signs indicate the contrary.

\section{Results}


Socioeconomic characteristics of the market garden of the study area are presented in (Tab. 2). Based on initial observations, the mean age of the producers in the area is 42 years, with primary level as the mean educational level. About 0 to 25 family's members worked on the farm, with an average of 7 persons per farm. The average farm size was 2.6 hectares, indicating that producers operate on large areas of land, and produce a wide range of vegetable products in the region. Most of the producers $(94.1 \%)$, owned the agricultural land. Also, the results revealed that $74.82 \%$ of the producers of the study area claimed to have adverse health effects due to pesticide spraying activity, and very few $(21.67 \%)$ had received pesticides management training. In addition, $42.34 \%$ and $41.23 \%$ of the producers respectively, had knowledge and were aware about the effects of pesticides on health and the environment.

Our field investigations revealed that market garden producers use 4 main pesticide products (herbicides, insecticides, fungicides, nematicides). According to first stage of the producer's perception analysis shown in (Fig. 4), about $28 \%$ among them agreed that pesticides have a hazardous effect on health, while $34 \%$ strongly agree to this. In contrast, only $2 \%$ strongly believed that pesticides products are not hazardous to human health, and approximately $23 \%$ were neutral. In the same line, the study of [40] observed that there were few producers in Ethiopia who had a good understanding of the health implications.

For the second stage of perception analysis, producers were asked about their awareness of the health hazards of each product (Tab. 3). Thus, the analysis shows that about $63.93 \%$ and $74.62 \%$ of producers testify that insecticides and herbicides are among the extremely hazardous products, while $43.25 \%$ and 65. $36 \%$ consider fungicides and nematicides as strongly hazardous for their health.

Table 3

Health hazards perception of pesticides effects

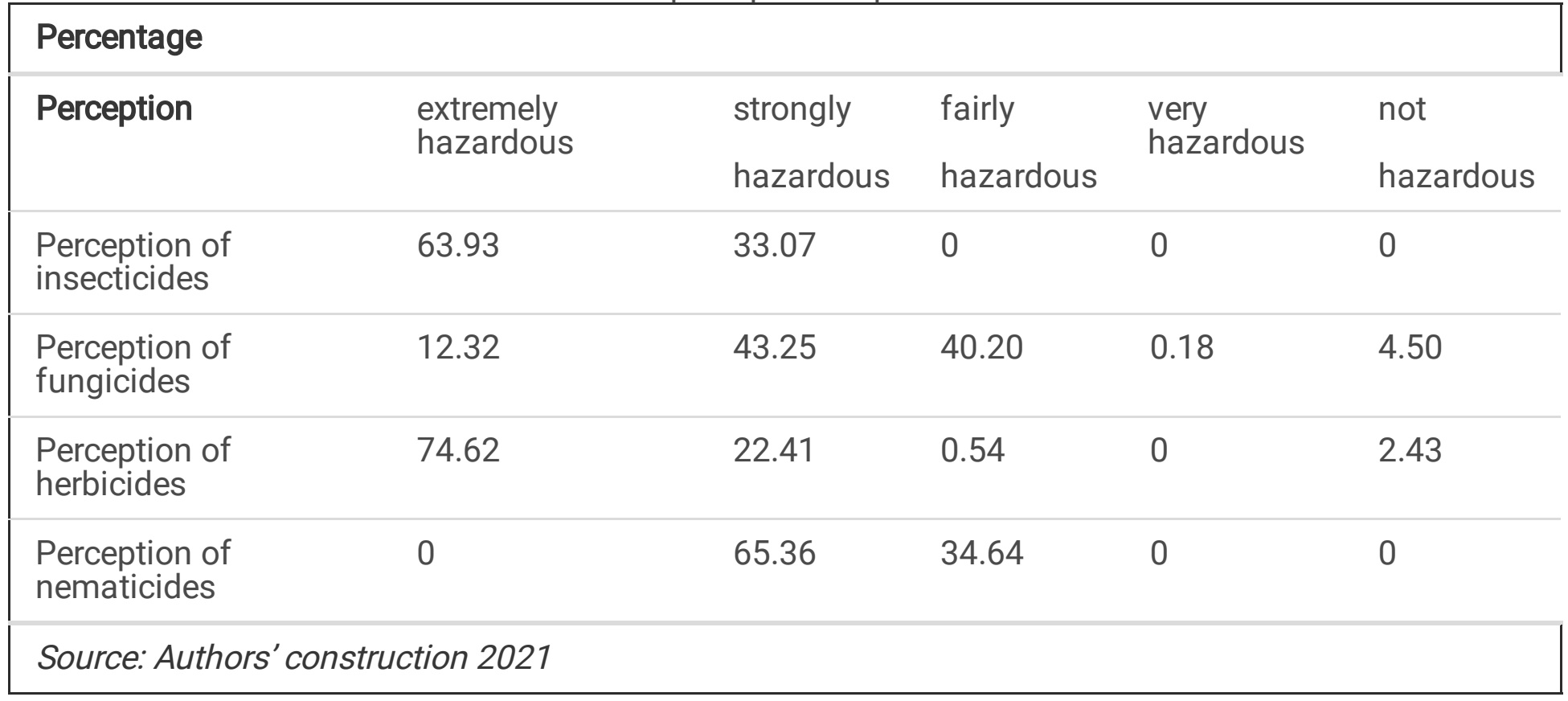


Furthermore, only $4.50 \%$ and $2.43 \%$ of producers respectively estimate that fungicides and herbicides were not hazardous for human health. All these results confirm the idea that the perception of pesticides effects by producers is sufficiently interesting to better understand their behavior in managing pesticide products on the farm. However, ${ }^{[41 a]}$ believe that they are still a few farmers in Africa, especially in Ethiopia that have a good knowledge of the health implications of pesticides application, while most producers still lack the training to improve their knowledge.

\section{Symptoms of intoxication reported by the exposed producer}

If we refer to earlier studies, most producers who use pesticides on their farms face numerous health problems. ${ }^{[41 \mathrm{~b}, 42]}$ Indeed, ${ }^{[43]}$ compared two producers' groups and indicated that toxic pollutants were found in higher concentrations in blood tests taken from cancer patients compared to controls. In (Tab. 4) we noted excessive sweating (61.07\%), general tiredness (61.96\%), nausea and vomiting (54.46\%), excessive salivation and loss of appetite (49.46\%), headaches (53.04\%), and dizzy (37.86\%) are among the main symptoms of health issues reported. Furthermore, confused and blurry vision $(30.18 \%)$, tremors of upper limbs $(28.75 \%)$ and convulsions $(26.79 \%)$ were also attested by the producers.

Table 4: Diseases symptoms reported by producers suffering pesticide poisoning

\begin{tabular}{|c|c|c|}
\hline Pictogram & Health symptoms & Percentage/Total (560) \\
\hline 承 & Dizzy & $37.86(212)$ \\
\hline 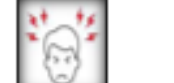 & Headaches & $53.04(297)$ \\
\hline & Excessive sweating & $61.07(342)$ \\
\hline & Confused and blurry vision & $30.18(169)$ \\
\hline & Nausea and vomiting & $54.46(305)$ \\
\hline & Tremors of upper limbs & $28.75(161)$ \\
\hline 论 & Convulsions & $26.79(150)$ \\
\hline 8 & $\begin{array}{c}\text { Excessive salivation and loss of } \\
\text { appetite }\end{array}$ & $49.46(277)$ \\
\hline int: & General tiredness & $61.96(347)$ \\
\hline
\end{tabular}

Source: Authors' construction 2021

In the literature a similar the study from ${ }^{[44]}$ indicated that after spraying pesticides, skin irritation and stomach ache after inhalation seemed to be the most common symptoms of poisoning. Just like this 
author, several studies have highlighted a variety of approaches to assessing the effects of pesticides on producers' health. The vast majority have confirmed their significant role in the development of various health complications such as chronic diseases, degenerative diseases, neuronal disorders and certain cancers. It would be therefore imperative to consider the implementation of structured interventions to reduce exposure to health risks.

\section{Correlation between the effect of pesticides and producers' perception of risk}

The results of the Pearson's point biserial correlation and Spearman's correlation tests between producers' perceptions of risks and their socioeconomic characteristics are presented in (Tab. 5). The first observations indicate that producers' perception had significant and positive correlations at the $1 \%$ level of significance with the age, level of education, training on pesticide management, health effects, and knowledge. While sex, awareness, pesticides training were significant at $5 \%$ and Membership of rural organization and experience were at $10 \%$ level of significance. In contrast, household size and farm area showed a negative and non-significant correlation with producers' perception.

Table 5

Correlations between producers' risk perception and socioeconomic characteristics.

\begin{tabular}{|lllll|}
\hline Variables & Correlation coefficient & p-value & & Correlation type \\
\hline Age & 0.0453 & 0.000 & $* \star *$ & Spearman \\
\hline Sex & -0.0364 & 0.009 & $* *$ & Point biserial \\
\hline Education & 0.0022 & 0.000 & $* * *$ & Spearman \\
\hline Exp & -0.0033 & 0.093 & $*$ & Spearman \\
\hline Membership & 0.0633 & 0.013 & $*$ & Point biserial \\
\hline Pesti_training & 0.0087 & 0.006 & $* *$ & Point biserial \\
\hline Size & 0.0026 & 0.9517 & & Spearman \\
\hline Area & -0.0261 & 0.5382 & & Spearman \\
\hline Health & 0.0165 & 0.000 & $* * *$ & Point biserial \\
\hline Knowledge & 0.0754 & 0.000 & $* * *$ & Spearman \\
\hline Awareness & -0.0548 & 0.008 & $* *$ & Spearman \\
\hline Source: Authors' ${ }^{\prime}$ construction 2021 & & & \\
\hline
\end{tabular}

Significant at $p<0.01$;__Significant at $p<0.05$;_Significant at $p<0.10$.

Determinants of market garden producers' risk perception of pesticides effects 
The estimated results of the producers' perceptions of pesticides effects using an ordered Logit model through the maximum likelihood approach are presented in (Tab. 6). Furthermore, in order to measure the robustness of the relationship between dependent variable and socioeconomic parameters we have analyzed and interpreted the coefficients of the statistical regression.

Table 6 Estimated results of the producers' risk perception of pesticide using the ordered Logit model.

\begin{tabular}{|lllllll|}
\hline & Estimate & Std. Err & Sig & & Lower bound & Upper bound \\
\hline Age & .024802 & .0122916 & 0.044 & $* *$ & .0007109 & .048893 \\
\hline Sex & -.148876 & .1603057 & 0.353 & & -.463066 & .1653207 \\
\hline Education & .002845 & .1094798 & 0.079 & $* *$ & -.2117309 & .2174222 \\
\hline Exp & -.01308 & .0145746 & 0.036 & $* *$ & -.0416539 & .0154751 \\
\hline Membership & .323127 & .1734207 & 0.062 & $*$ & -.0167759 & .6630209 \\
\hline Area & -.086683 & .0502886 & 0.085 & $*$ & -.1852474 & .0118804 \\
\hline Ownership & -.546845 & .3468379 & 0.115 & & -1.226635 & .1329449 \\
\hline Pesti_training & .051919 & .1911596 & 0.000 & $* * *$ & -.3227466 & .4265851 \\
\hline Size & -.023241 & .0262506 & 0.376 & & -.0746902 & .0282101 \\
\hline Health & .035909 & .2021921 & 0.009 & $* * *$ & -.3603795 & .432199 \\
\hline Knowledge & .048642 & .1902586 & 0.000 & $* * *$ & -.2411678 & .3526187 \\
\hline Awareness & -023759 & .2047321 & 0.000 & $* * *$ & -.1937836 & .0127489 \\
\hline Source: Authors' construction 2021 & & & & \\
\hline
\end{tabular}

Significant at $p<0.01$;__Significant at $p<0.05$;_Significant at $p<0.10$.

Thus, this shows that there is a positive relationship between the producers' risk perceptions and some variables like age $(\beta=.2480)$, education level of producers $(\beta=.00284)$, health $(\beta=.0359)$, training on pesticides $(\beta=.0519)$ and knowledge $(\beta=.0486)$. Furthermore, the results of this table reveals that there are four variables (training on pesticides, health, knowledge, and awareness) were at a $1 \%$ level of significance $p<0.01$, while age, education level, producers 'experience were significant at $5 \%$ $p<0.05$, and membership of rural organization and total area at $10 \%$ of significance $p<0.10$ respectively. These results are globally confirmed by other existing studies like the one of. ${ }^{[22,45]}$ Other statistical results, including pseudo $R^{2}$ measures (0.174), log-likelihood statistics (-265), and LR $\chi^{2}$ (108.53), indicate the robustness of the ordered Logit model. 
Table 7

Marginal effects of producers' health-related risk perceptions of pesticides effects

\begin{tabular}{|lllllll|}
\hline & dy/dx & Std. Err & Sig & & Lower bound & Upper bound \\
\hline Age & -.0026009 & .00131 & 0.047 & $\star \star$ & -.005162 & -.00004 \\
\hline Sex & .0156117 & .01687 & 0.355 & & -.017454 & .048677 \\
\hline Education & -.0002984 & .01148 & 0.979 & & -.0228 & .022203 \\
\hline Exp & .0013726 & .00153 & 0.071 & $\star \star$ & -.001633 & .004378 \\
\hline Membership & -.034733 & .01928 & 0.072 & $*$ & -.072519 & .003053 \\
\hline Area & .0090902 & .00532 & 0.088 & $*$ & -.001337 & .019517 \\
\hline Ownership & .0487679 & .02614 & 0.062 & $*$ & -.002464 & .185403 \\
\hline Pesti_training & -.0053923 & .01967 & 0.784 & & -.043948 & .033163 \\
\hline Size & .0024371 & .00276 & 0.377 & & -.002969 & .007843 \\
\hline Health & -.0037875 & .02145 & 0.006 & $* \star *$ & -.045824 & .038249 \\
\hline Knowledge & .04864219 & .00287 & 0.000 & $* \star *$ & -.034573 & .025786 \\
\hline Awareness & -00265972 & .001391 & 0.000 & $* \star *$ & -.0246579 & .013546 \\
\hline Source: Authors' construction & 2021 & & & & \\
\hline
\end{tabular}

_Significant at $p<0.01 ;$ Significant at $p<0.05 ;$ Significant at $p<0.10$.

In (Tab. 7), the marginal effects indicate that market garden producers in the study area are very likely to perceive the use of pesticides for food production as leading to significant health and biodiversity impacts.

\section{Discussing The Microeconomic Framework Of Pesticide Use: A Need For Structural Changes}

In the field of pesticides researches, producers risk perception seems to be an important issue in vulgarizing the safe management of pesticides in the farms. Yet, there still much emphasis on education and technical training of producers for their safe handling in Cameroon. Considering the lack of empirical data in the literature on this concern, this paper sheds light on the perception of health-related risks among agricultural producers. Through the context of this study's perspective, it is our aim to establish the theoretical link between the main socioeconomic characteristics and producers' perception of the risk of pesticide effects. But also, discussion about health symptoms of pesticide poisoning which provides 
at the end important recommendations for policymakers, association of producers, rural communities and so far health agencies. Thus, the coefficients of the ordered Logit model which represent age, level of education, training on pesticides revealed that it is a positive and significant relation on the risk perception of pesticide effects and some socioeconomic variables. Indeed, the few years of conventional learning that are completed by producers indicate that education, as a source of human capital, has positive effects on health risk perception.

This empirical evidence have been confirmed earlier by ${ }^{[46,47]}$ who concluded that education provides well informed producers with better technical capacities for effective pesticide use. Furthermore, ${ }^{[47]}$ showed that educated producers are more aware of the dangers of mishandling pesticides and thus adopt the necessary protective measures to reduce their level of exposure to harmful products. Although the educational level is very low among the producer community of our study area, unexpectedly, his related coefficient was found to be positive and significant.

The adverse health effects brought by the overuse of pesticides have led to a high perception of the risks. Our results are consistent with the conclusion of ${ }^{[48]}$ for whom the adverse health effects faced by producers could strongly influence risk perception. In the same line, ${ }^{[49]}$ observed that producers confronted with the adverse health effects of pesticides "were more expected to consider pesticides as very hazardous [...]." Following this empirical observation, underlying evidence indicates a relationship between pesticide poisoning and some specific diseases such as respiratory problems ${ }^{[50]}$ or breast cancer ${ }^{[51]}$. Moreover, the toxic effects of pesticides were investigated, and the results showed that the farmers in the selected study area faced different health-related issues (Tab. 4). Among all health problems identified, excessive sweating, general tiredness, nausea and vomiting, excessive salivation and loss of appetite, headaches, and dizzy constitute the major symptoms reported by the producers living in our study area.

In terms of access to technical training on pesticides, this study showed that it definitely reduces health risks for producer. Indeed, some studies have stated that in addition to receiving pesticides training, an access to extension services is important for enlightening producers' knowledge, and awareness of the rational spraying of pesticides ${ }^{[45]}$. Thus, the level of perception in our investigation was significantly associated with farmers' knowledge and awareness, which according to ${ }^{[52]}$, are usually transmitted through online media, and multiple additional sources. Also, an empirical research study piloted by [53] highlighted that the social community in rural areas facilitated the flow of information, which in turn influenced local farmers' decisions about the adoption of new agricultural practices.

A Similar results have been established by ${ }^{[54]}$ who observed that awareness is generally based on previous experiences, but generally, farmers receive different information concerning modern farming from development workers, traders, input suppliers, social networks, and farm training schools. At the end, ${ }^{[55]}$ concluded that knowledge and awareness critically determine how health risks are perceived and systematically handled by farmers. Unfortunately, the main economic consequences of such issues are 
an increase in health costs associated with these diseases. Meanwhile, the issue of health costs can be mitigated through health insurance. Unfortunately, health insurance in Cameroon is not properly widespread for certain reasons, such as credit constraints and information asymmetry about health insurance.

\section{Conclusion And Agricultural Policies Recommendations}

In this paper, we have examined the health hazard and main determinants of market garden producers' risk perception toward pesticides effects. This is based on a field survey that was conducted in 2021, and socioeconomic information collected from 560 producers from west region of Cameroon. The results of the ordered Logit model indicated that the age, education, health effects, training on pesticides management, producers' knowledge and awareness, had a positive and significant influence on producers' perceptions of pesticides effects. Our results are in line with the empirical evidence of ${ }^{[56]}$ who confirm that pesticide spraying are the outcome of farmers' behavior and the influence of social structure.

The present method used in this research is one of the first attempts to analyze Cameroonian market garden producers' perceptions towards pesticides effects based on the TPB theory, which indicates good efficiency in analyzing producers' perceptions. The results further show that in addition to individual characteristics, producers' behavior under the influence of subjective norms, influences their intentions to adopt specific behavior. Due to an increase demand of food crops (including market garden products) and the ever-growing population in Cameroon, specifically in rural areas, a sufficiently robust set of policy initiatives are required to ensure the reduction of health risks from pesticides spraying.

Founded on the previous evidence, this paper suggests that information campaigns should be conducted to improve producers' perceptions so that they can implement risk reduction strategies. This could be accomplished by increasing producers' knowledge of pesticides and initiating pesticide health safety education with qualifications certified programs through ministry of agriculture and rural development. These trainings should specifically address issues related to good agricultural practices on spraying pesticides in the field, storage and waste management, but also on producer health related to pesticide toxicity. In addition, retailers who are the main source of information on pesticides in rural areas should be oriented to better assist farmers. Other intervention strategies through routine investigation and strict monitoring by agricultural field officers at the retail and farm levels should also be strengthened.

Furthermore, the Cameroonian government through ministry of agriculture should strictly regulate the commercialization of chemicals such as Dichlorodiphenyltrichloroethane (DDT) as there are still widely sprayed on food and non-food crops in Cameroon. ${ }^{27]}$

Other government policy approaches include involving media actors in the extension of more secure food production and improving the role of extension workers through stepwise supervision. In addition, the government could further develop partnerships with some organic food producers and traders to ensure product safety via a national traceability system such as Good Agricultural Practices (GAPs) in the certification system. The implementation of these GAPs at national level would help to control the 
inappropriate use of pesticides as exceeding the maximum residual limit (MRL) is technically unsustainable. Finally, it should be emphasized that consumer perception has not been captured here. As such, future research would need to cover a wider range by analyzing consumer opinions on the health risks of pesticide residues with broader data.

\section{Declarations}

\section{-Ethics approval and consent to participate}

Not applicable.

\section{-Consent for publication}

Not applicable.

\section{-Availability of data and materials}

All data generated or analyzed during this research are included in this article.

\section{-Competing Interest}

The authors declare that the study was conducted in the absence of any conflicting commercial or financial relationships.

\section{-Funding}

Not applicable.

\section{-Authors' contributions}

The paper has been prepared by all the authors. Kaldjob Christian Bernard conceived the study and revised the manuscript. Simo Brice Herman, Kaldjob Christian Bernard and Nso Ngang Andre contributed to data searching screening, extraction and data analysis, Kaldjob Christian Bernard, Tata Ngome Precillia and Bamou Tankoua Lydie revised the paper and approved the final version to be submitted. Douya Emmanuel participated in screening the titles, abstracts and full text screening, he also advised on the analysis of the data and revised the manuscript. Finally, all authors read and approved the final manuscript.

\section{-Acknowledgements}

The authors are especially grateful to all the courageous producers of west region of Cameroon for providing all the field informations in order to facilitate the achievement of this research.

\section{References}


1. Cooper Jerry; Hans Dobson. The benefits of pesticides to mankind and the environment. Crop Protection, 2007. doi.org/10.1016/j.cropro.2007.03.022

2. Mehmood Yasir; Muhammad Arshad;; Harald Kaechele; Nasir Mahmood; Rong Kong. Pesticide Residues, Health Risks, and Vegetable Farmers' Risk Perceptions in Punjab, Pakistan. Human and Ecological Risk Assessment: An International Journal 2021. doi.org/10.1080/10807039.2020.1776591.

3. Alavanja, Michael CR. Introduction: Pesticides use and exposure, extensive worldwide. Reviews on environmental health 2009. 24 (4): doi.org/10.1515/Reveh.2009.24.4.303

4. FAO; FIDA; OMS; PAM; UNICEF. L'État de la sécurité alimentaire et de la nutrition dans le monde: Se prémunir contre les ralentissements et les fléchissements économiques. Rome: Organisation des Nations Unies pour l'Alimentation et l'Agriculture 2019.

5. INS. Agriculture in Annuaire statistique du Cameroun, 2015. 232-55. Institut National de la Statistique.

6. Galani Yamdeu Joseph Hubert; Micheal Houbraken;; Abukari Wumbei,; Joseph Fovo Djeugap;; Daniel Fotio. Evaluation of 99 pesticides residues in major agricultural products from the western highlands zone of Cameroon using QuEChERS method extraction and LC-MS/MS and GC-ECD analyses. Foods, MDPI edition 2018. 7 (184): doi: 10.3390/foods7110184

7. Sonchieu, Jean,; Edouard Nantia Akono; Cheche Tanwi Ngwamitang,; Benoït Martin Ngassoum. Heath Risk among Pesticide Sellers in Bamenda Cameroon and Peripheral Areas. Environmental Science and Pollution Research 201825 (10): doi.org/10.1007/s11356-018-1243-8.

8. Sonchieu, jean;; Bitsoga Marie Gracile; Ngassoum Martin Benoit. Characterization of Personal Clothing Worn by Pesticide Sprayers in Foumbot Agricultural Area Cameroon. Agricultural Sciences 201910 (08): doi.org/10.4236/as.2019.108080.

9. Pouokam Guy; William Lemnyuy Album, ; Alice Ndikontar. A Pilot Study in Cameroon to Understand Safe Uses of Pesticides in Agriculture, Risk Factors for Farmers' Exposure and Management of Accidental Cases. Toxics 2017 5(40): doi.org/10.3390/toxics5040030

10. Popp, József,; Károly Pető; János Nagy. Pesticide productivity and food security. A review. Agronomy for sustainable development 201333 (1): 243-55. doi.org/10.1007/s13593-012-0105-x

11. Thundiyil Josef G,; Judy Stober; Nida Besbelli,; Jenny Pronczuk. Acute pesticide poisoning: A proposed classification tool. Bulletin of the World Health Organization 2008 86: 205-9. doi.org/10.2471/BLT.08.041814

12. Brice Nkontcheu Daniel; Patricia Asanga; Bi Fai,; Ngameni Tchamadeu Norbert; Mpoame Mbida. Environmental and Human Health Assessment in Relation to Pesticide Use by Local Farmers and the Cameroon Development Corporation, Fako Division, South-West Cameroon. European Scientific Journal, ESJ 201713 (21): 454. doi.org/10.19044/esj.2017.v13n21p454

13. Reganold, John $P_{\text {; }}$ Jonathan M Wachter. Organic agriculture in the twenty-first century. Nature plants 20162 (2): 1-8. 10.1038/nplants.2015.221 
14. Bertolote, J. M.; A. Fleischmann; M. Eddleston;; D. Gunnell. Deaths from Pesticide Poisoning: A Global Response British Journal of Psychiatry 2006189 (3): doi.org/10.1192/bjp.bp.105.020834

15. Poisson, Marie-Christine,; Daniel R Garrett,; Audrey Sigouin,; Marc Bélisle; Dany Garant; JeanPhilippe Bellenger. Assessing pesticides exposure effects on the reproductive performance of a declining aerial insectivore. Ecological Applications 2021. doi.org/10.1002/eap.2415

16. Philippe Verger; Agamy Neveen,; Anshasi Marwa; Al-Yousfi Ahmad Basel. Occurrence of pesticide residues in fruits and vegetables for the Eastern Mediterranean Region and potential impact on public health. Food Control 2021 119: doi.org/10.1016/j.foodcont.2020.107457

17. Brito, Vanessa D; Fernanda Achimón,; Romina P Pizzolitto; Agripina Ramírez Sánchez;; Elisa A Gómez Torres. An alternative to reduce the use of the synthetic insecticide against the maize weevil Sitophilus zeamais through the synergistic action of Pimenta racemosa and Citrus sinensis essential oils with chlorpyrifos. Journal of Pest Science 202194 (2): 10.1007/s10340-020-01264-0

18. Son Diakalia;, Schémaeza Bonzi,; Bruno Schiffers,; Irénée Somda. Assessment of tomato (Solanum Lycopersicum L.) producers' exposure level to pesticides, in Kouka and Toussiana (Burkina Faso). International journal of environmental research and public health 201815 (2): doi.org/10.3390/ijerph15020204

19. Endsley, Mica R. Measurement of situation awareness in dynamic systems. Human factors 199537 (1): 65-84. doi.org/10.1518/001872095779049499

20. Afroz, Rafia,; Hasanul Banna,; Muhammad Mehedi Masud,; Rulia Akhtar;; Siti Rohani Yahaya.. Household's Perception of Water Pollution and Its Economic Impact on Human Health in Malaysia Desalination and Water Treatment 2015. doi.org/10.1080/19443994.2015.1006822

21. Ahmed Adeel,; Imran Shafique. Perception of Household in Regards to Water Pollution: An Empirical Evidence from Pakistan. Environmental Science and Pollution Research 201926 (9): 8543-51. doi.org/10.1007/s11356-019-04273-4.

22. Abdollahzadeh Gholamhossein,; Mohammad Sharif Sharifzadeh. Perceptions of the Beneficial and Harmful Effects of Pesticides among Iranian Rice Farmers Influence the Adoption of Biological Control. Crop Protection 2015 75: 124-31. doi.org/10.1016/j.cropro.2015.05.018.

23. Parveen Sultana,; Nobukazu Nakagoshi,; Ayako Kimura.. Perceptions and Pesticides Use Practices of Rice Farmers in Hiroshima Prefecture, Japan. Journal of Sustainable Agriculture 200322 (4): doi.org/10.1300/J064v22n04_03.

24. Luis silvia,; Maria Luísa Lima,; Lucía Poggio;; Juan Ignacio Aragonés;; Audrey Courtier;; Benoit Roig;; Carole Blanchard. Lay people and experts' risk perception of pharmaceuticals in the environment in Southwestern Europe. Regulatory Toxicology and Pharmacology 2020 117: doi.org/10.1016/j.yrtph.2020.104783

25. Barraza, Douglas, Kees Jansen, Catharina Wesseling, Berna van Wendel.. Pesticide Risk Perceptions among Bystanders of Aerial Spraying on Bananas in Costa Rica. Environmental Research 2020189. 109877. doi.org/10.1016/j.envres.2020.109877. 
26. Boissonot, Romain. Risques sanitaires et perception chez les agriculteurs utilisateurs de produits phytopharmaceutiques. Conservatoire National des Arts et Métiers 2014. tel.archives-ouvertes.fr/tel01136658

27. Galani, Yamdeu Joseph Hubert; Michael Houbraken; Abukari Wumbei,; Joseph Fovo Djeugap; Daniel Fotio,; Yun Yun Gong. Monitoring and Dietary Risk Assessment of 81 Pesticide Residues in 11 Local Agricultural Products from the 3 Largest Cities of Cameroon. Food Control 2020 118: 107416. doi.org/10.1016/j.foodcont.2020.107416

28. Icek Ajzen. The theory of planned behavior. Organizational behavior and human decision process, Elsevier, 199150 (2): 179-211. doi.org/10.1016/0749-5978 (91)90020-T.

29. Wang Shanyong; Jing Wang,; Shoufu Lin,; Jun Li.. Public perceptions and acceptance of nuclear energy in China: The role of public knowledge, perceived benefit, perceived risk and public engagement. Energy Policy 2019 126: 352-60. doi.org/10.1016/j.enpol.2018.11.040

30. Wang, Jianhua,; Junying Tao,; Chenchen Yang,; May Chu,; Honming Lam. A general framework incorporating knowledge, risk perception and practices to eliminate pesticide residues in food: A structural equation modelling analysis based on survey data of 986 Chinese farmers. Food Control 2017 80: 143-50. doi.org/10.1016/j.foodcont.2017.05.003

31. Ru, Xingjun,; Shanyong Wang; Shuai Yan. Exploring the effects of normative factors and perceived behavioral control on individual's energy-saving intention: An empirical study in eastern China. Resources, Conservation and Recycling 2018 134: doi.org/10.1016/j.resconrec.2018.03.001

32. Gao Lan; Shanyong Wang,; Jun Li;; Haidong Li. Application of the extended theory of planned behavior to understand individual's energy saving behavior in workplaces. Resources, Conservation and Recycling 2017 127: dx.doi.org/10.1016/j.resconrec.2017.08.030

33. Ataei Pouria,; Saeed Gholamrezai,; Reza Movahedi; Vahid Aliabadi.. An analysis of farmers' intention to use green pesticides: The application of the extended theory of planned behavior and health belief model. Journal of Rural Studies 2021 81: doi.org/10.1016/j.jrurstud.2020.11.003

34. Bagheri Asghar;; Abolmohammad Bondori,; Christos A. Damalas. Modeling cereal farmers' intended and actual adoption of integrated crop management practices. Journal of Rural Studies 201970 : 58-65. doi.org/10.1016/j.jrurstud.2019.05.009

35. Bakker L. J Sok; W Van Der Werf,; FJJA Bianchi. Kicking the Habit: What Makes and Breaks Farmers' Intentions to Reduce Pesticide Use? Ecological Economics 2021 180: doi.org/10.1016/j.ecolecon.2020.106868

36. Doran Elizabeth MB; Asim Zia,; Stephanie E Hurley;; Yushiou Tsai,; Christopher Koliba,; Carol Adair; Rachel E Schattman; Donna M Rizzo. Social-psychological determinants of farmer intention to adopt nutrient best management practices: Implications for resilient adaptation to climate change. Journal of Environmental Management 2020 276: doi.org/10.1016/j.jenvman.2020.111304

37. Mergia Mekuria Teshome; Ermias Deribe Weldemariam,; Girma Tilahun Yimer. Small-scale Farmer Pesticide Knowledge and Practice and Impacts on the Environment and Human Health in Ethiopia. Journal of Health Pollution 202111 (30): doi.org/10.5696\%2F2156-9614-11.30.210607 
38. Dan Pan,; Mimi He; Fanbin Kong. Risk attitude, risk perception, and farmers' pesticide application behavior in China: A moderation and mediation model. Journal of Cleaner Production 2020276 : doi.org/10.1016/j.jclepro.2020.124241

39. Minader, Agriculture. In Annuaire statistique du Cameroun, 2017 24. Cameroun: Institut National de la Statistique.

40. Mgale Yohana James; ; Yan Yunxian. Price Risk Perceptions and Adoption of Management Strategies by Smallholder Rice Farmers in Mbeya Region, Tanzania. Cogent Food \& Agriculture 20217 (1): 1919370. doi.org/10.1080/23311932.2021.1919370

41. Teklu, Berhan,; M., Paulien,; I. Adriaanse; Mechteld M.S,; Ter Horst;; John W. Deneer; Paul J. Van den Brink. Surface Water Risk Assessment of Pesticides in Ethiopia. Science of the Total Environment 2015 508: 566-74. doi.org/10.1016/j.scitotenv.2014.11.049.

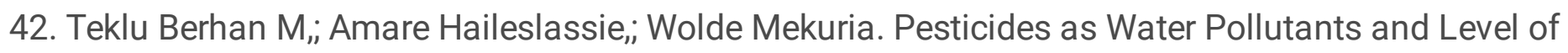
Risks to Environment and People: An Example from Central Rift Valley of Ethiopia. Environment, Development and Sustainability 2021, doi.org/10.1007/s10668-021-01658-9.

43. Jaga, Kushik; Denton Brosius. Pesticide exposure: human cancers on the horizon. Reviews on environmental health 1999 14 (1): 39-50. doi.org/10.1515/Reveh.1999.14.1.39

44. Solomon Gina,; OA Ogunseitan,; Jan Kirsch.. Pesticides and Human Health A Resource for Health Care Professionals 2000. escholarship.org/uc/item/1kh1m1z8\#main

45. Charlier C. Breast Cancer and Serum Organochlorine Residues. Occupational and Environmental Medicine 200360 (5): 348-51. doi.org/10.1136/oem.60.5.348.

46. Raimi, Morufu Olalekan. Self-Reported Symptoms on Farmers Health and Commonly Used Pesticides Related to Exposure in Kura, Kano State, Nigeria. Public Health 2021 (1): ssrn.com/abstract $=3771437$

47. Khan Muhammad;; Hafiz Zahid Mahmood;; Christos A Damalas. Pesticide use and risk perceptions among farmers in the cotton belt of Punjab, Pakistan. Crop Protection 2015 67: 184-90. doi.org/10.1016/j.cropro.2014.10.013

48. Eleftherohorinos, llias G. Pesticide Exposure, Safety Issues, and Risk Assessment Indicators ». International Journal of Environmental Research and Public Health 20118 (5): 1402-19. doi.org/10.3390/ijerph8051402

49. Gaber, Sherine; Soha Abdel-Latif. Effect of Education and Health Locus of Control on Safe Use of Pesticides: A Cross Sectional Random Study. Journal of Occupational Medicine and Toxicology 20127 (1): doi.org/10.1186/1745-6673-7-3

50. Abdollahzadeh, Gholamhossein; Mohammad Sharif Sharifzadeh,; Christos A. Damalas. Perceptions of the Beneficial and Harmful Effects of Pesticides among Iranian Rice Farmers Influence the Adoption of Biological Control. Crop Protection 2015 75: doi.org/10.1016/j.cropro.2015.05.018

51. Ye Ming,; Jeremy Beach,; Jonathan Martin,; Ambikaipakan Senthilselvan. Occupational Pesticide Exposures and Respiratory Health. International Journal of Environmental Research and Public Health 201310 (12): 6442-71. doi.org/10.3390/ijerph10126442. 
52. Alavanja, Michael C. R; Matthew K. Ross;; Matthew R. Bonner. Increased Cancer Burden among Pesticide Applicators and Others Due to Pesticide Exposure: Pesticides Exposure and Cancer. CA: A Cancer Journal for Clinicians 201363 (2): 120-42. doi.org/10.3322/caac.21170

53. Mahmood, Nasir; Muhammad Arshad;; Harald Kaechele; Muhammad Faisal Shahzad;; Ayat Ullah,; Klaus Mueller. Fatalism, Climate Resiliency Training and Farmers' Adaptation Responses: Implications for Sustainable Rainfed-Wheat Production in Pakistan. Sustainability 202012 (4): 1650. doi.org/10.3390/su12041650.

54. Bouma, Jetske; Erwin Bulte; Daan Van Soest. Trust and cooperation: Social capital and community resource management. Journal of environmental economics and management 200856 (2): 155-66. doi.org/10.1016/j.jeem.2008.03.004

55. Keraita, Bernard,; Pay Drechsel,; Razak Seidu,; Priyanie Amerasinghe; Olufunke 0 Cofie,; Flemming Konradsen. Harnessing farmers' knowledge and perceptions for health-risk reduction in wastewaterirrigated agriculture. In Wastewater Irrigation and Health 2009 363-80. Routledge.

56. Peres Frederico; Josino C. Moreira,; Karla M. Rodrigues;; Luz Claudio. Risk Perception and Communication Regarding Pesticide Use in Rural Work: A Case Study in Rio de Janeiro State, Brazil. International Journal of Occupational and Environmental Health 200612 (4): 400-407 doi.org/10.1179/oeh.2006.12.4.400.

57. Mengistie, Belay T.; Arthur P. J. Mol;; Peter Oosterveer. Pesticide Use Practices among Smallholder Vegetable Farmers in Ethiopian Central Rift Valley. Environment, Development and Sustainability 2017. 19 (1): 301-24. doi.org/10.1007/s10668-015-9728-9.

\section{Figures}




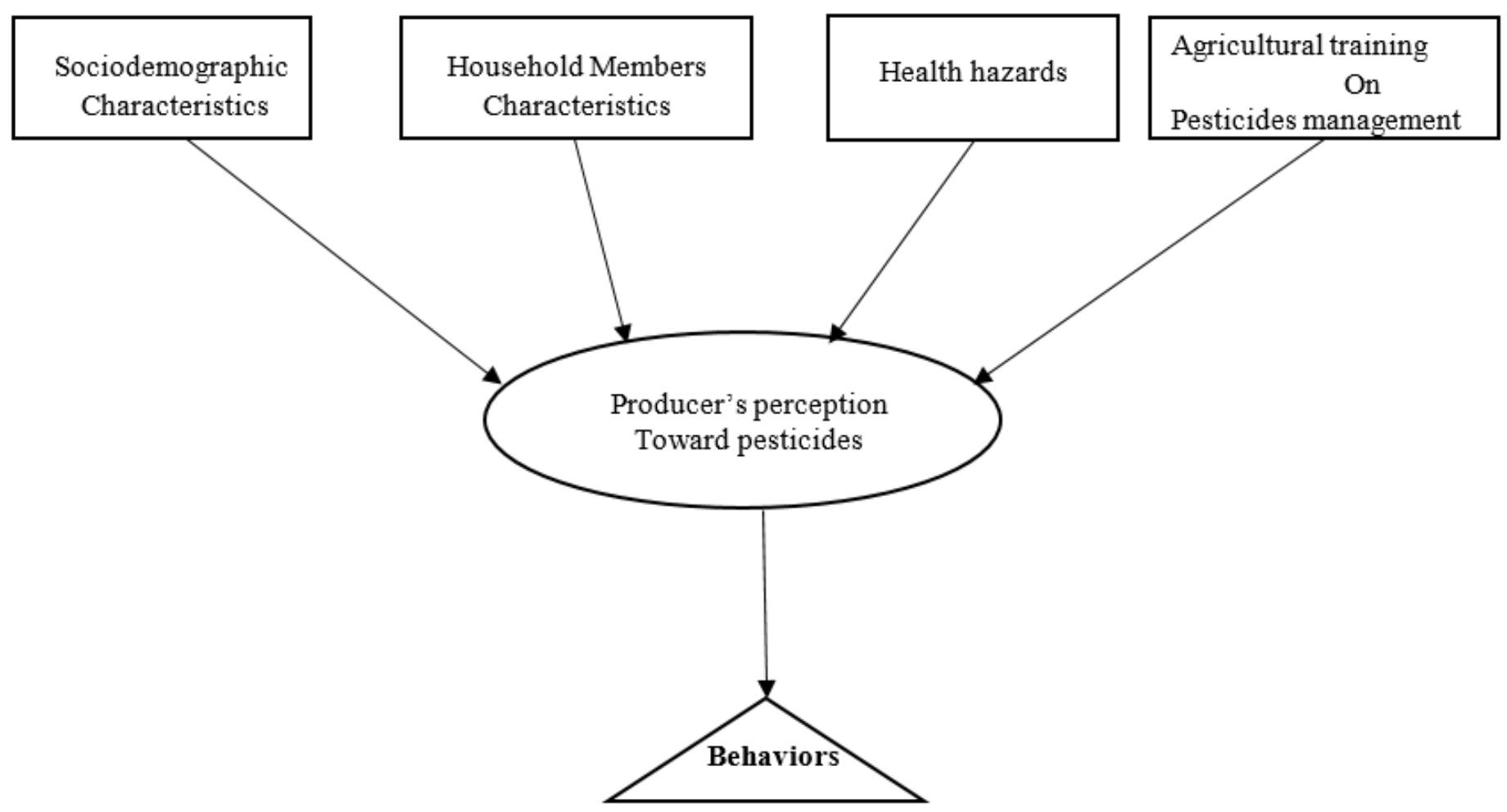

Figure 1

Theoretical framework of factors affecting producers' perception toward pesticide effects.

Source: authors' construction 2021 


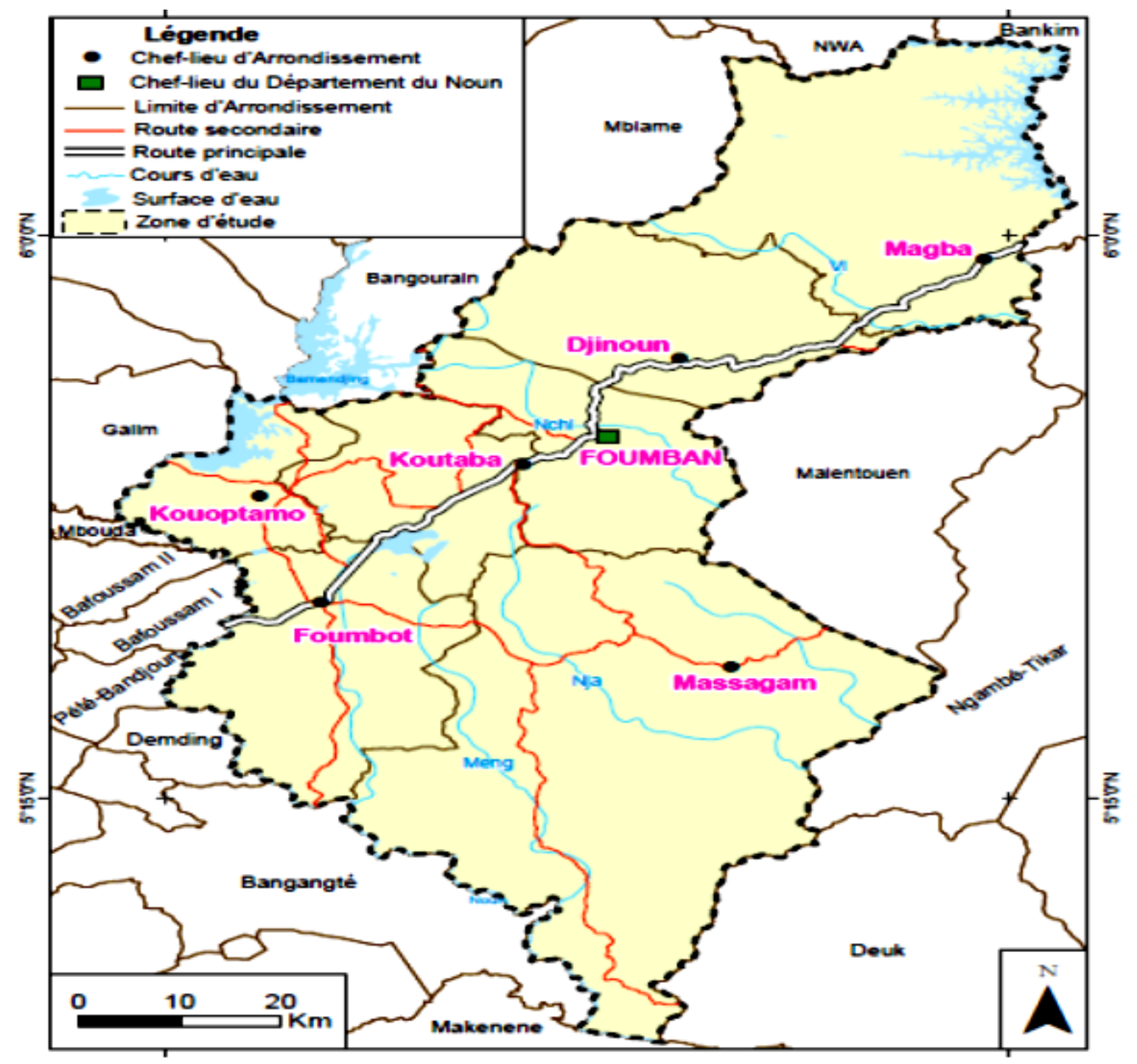

Figure 2

Study area Source: Authors' construction 2021 


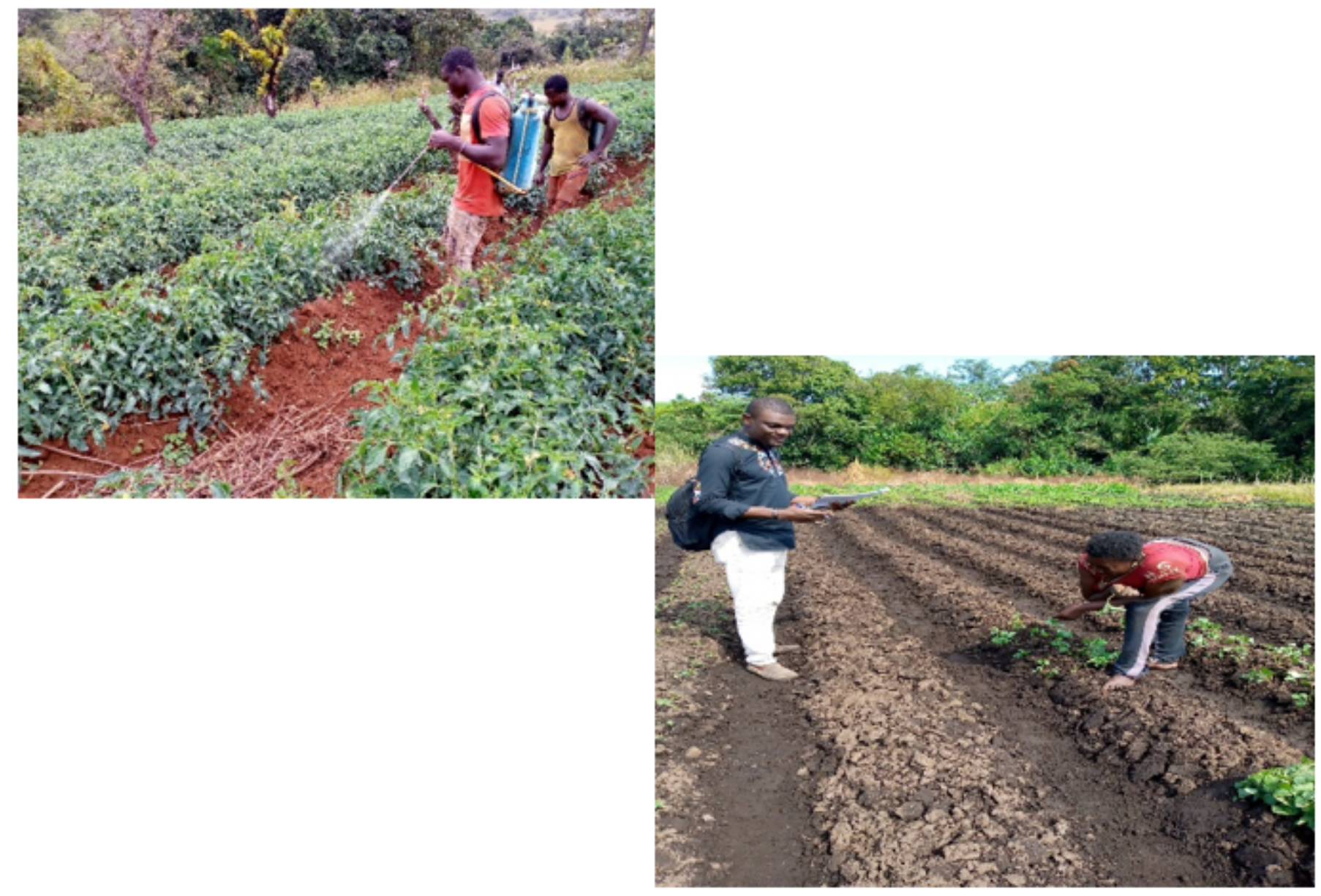

\section{Figure 3}

field survey with producer/ sprayer practicing without protective devices.

Source: Authors from field survey 2021 


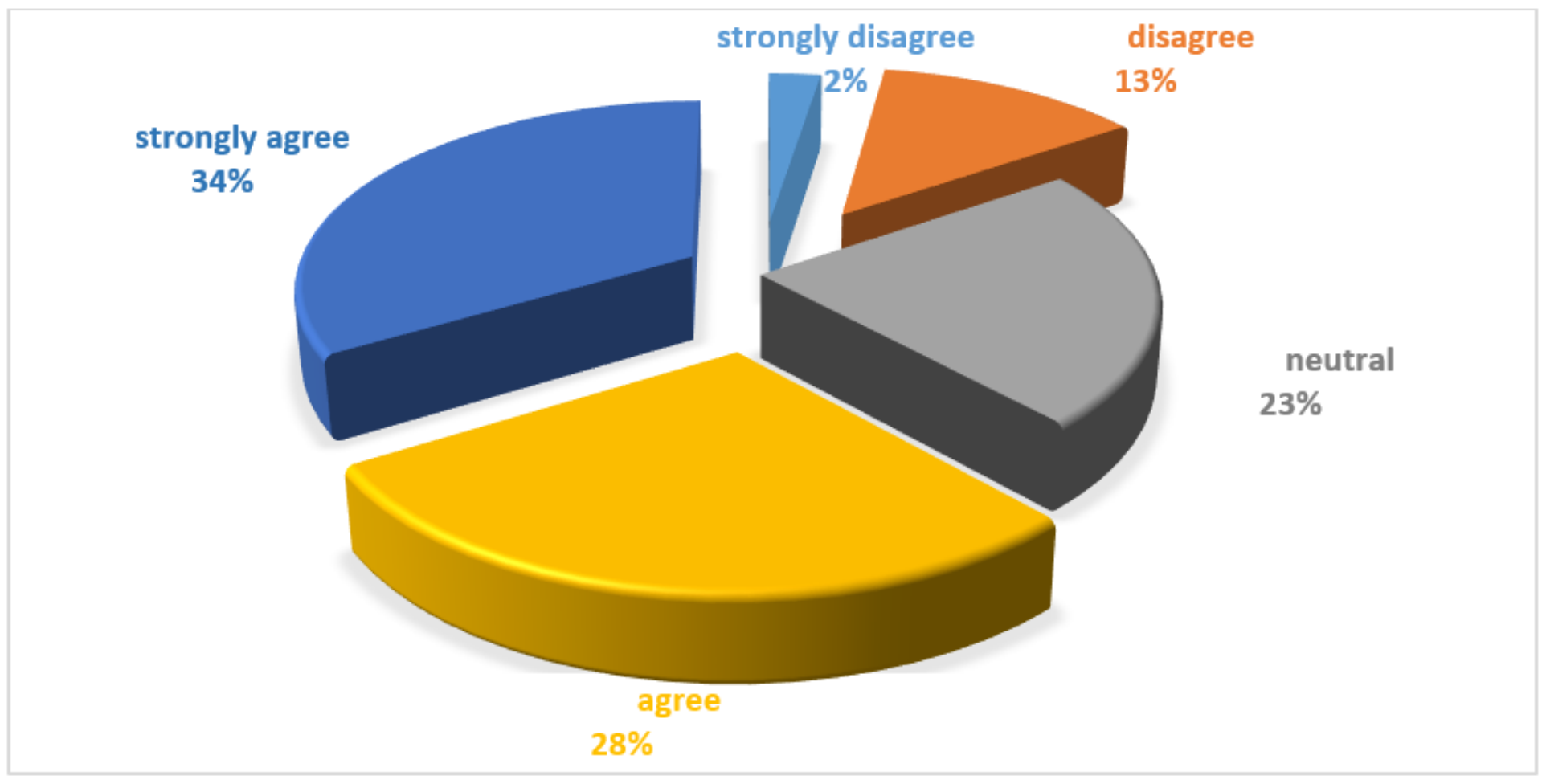

Figure 4

Producers' appreciation of pesticides risk

Source: authors' construction 2021 